\title{
Contribution by vertebrates to seed dispersal effectiveness in the Galápagos Islands: a community-wide approach
}

\author{
M. Nogales, ${ }^{1}$ A. González-Castro, ${ }^{1,7}$ B. Rumeu, ${ }^{2}$ A. Traveset, ${ }^{3}$ P. Vargas, ${ }^{4}$ \\ P. Jaramillo, ${ }^{5}$ J. M. Olesen, ${ }^{6}$ and R. H. Heleno ${ }^{2}$ \\ ${ }^{1}$ Island Ecology and Evolution Research Group (IPNA-CSIC), Canary Islands, Spain \\ ${ }^{2}$ Centre for Functional Ecology, Department of Life Sciences, University of Coimbra, Coimbra, Portugal \\ ${ }^{3}$ Institut Mediterrani d'Estudis Avançats (UIB-CSIC), Balearic Islands, Spain \\ ${ }^{4}$ Real Jardín Botánico (RJB-CSIC), Madrid, Spain \\ ${ }^{5}$ Charles Darwin Foundation, Puerto Ayora, Santa Cruz, Galápagos, Ecuador \\ ${ }^{6}$ Department of Bioscience, Aarhus University, Aarhus C, Denmark
}

\begin{abstract}
Seed dispersal and seedling recruitment are crucial phases in the life cycle of all spermatophyte plants. The net contribution of seed dispersers to plant establishment is known as seed dispersal effectiveness (SDE) and is defined as the product of a quantitative (number of seeds dispersed) and a qualitative (probability of recruitment) component. In Galápagos, we studied the direct contribution to SDE (number of seeds dispersed and effect on seedling emergence) provided by the five island groups of frugivores (giant tortoises, lizards, medium-sized passerine birds, small non-finch passerine birds, and finches) in the two main habitats in this archipelago: the lowland and the highland zones, and found 16 vertebrate species dispersing 58 plant species. Data on frequency of occurrence of seeds in droppings and number of seeds dispersed per unit area produced contrasting patterns of seed dispersal. Based on the former, giant tortoises and medium-sized passerines were the most important seed dispersers. However, based on the latter, small non-finch passerines were the most important dispersers, followed by finches and medium-sized passerines. The effect of disperser gut passage on seedling emergence varied greatly depending on both the disperser and the plant species. Although the contribution to SDE provided by different disperser guilds changed across plant species, medium-sized passerines (e.g., mockingbirds) provided a higher contribution to SDE than lava lizards in 10 out of 16 plant species analysed, whereas lava lizards provided a higher contribution to SDE than birds in five plant species. While both the quantitative and qualitative components addressed are important, our data suggests that the former is a better predictor of SDE in the Galápagos archipelago.

Key words: animal-plant interaction; frugivory; island ecology; ornithochory; saurochory; seedling emergence.
\end{abstract}

\section{INTRODUCTION}

The biota of oceanic islands is shaped by the simultaneous and continuous action of biogeographical, ecological, and evolutionary processes (Gorman 1979). To the colonization of islands by plants, seed dispersal is a crucial phase, and consequently, morphological traits that facilitate diaspore dispersal are shaped by natural selection (Ridley 1930). These traits are classified into different syndromes, according to the dispersal mechanisms that they tend to promote (Van der Pijl 1982). Among them, the internal transport of ingested seeds through animal guts (i.e., endozoochory) has been regarded as one of the "highways" in the colonization of oceanic islands (Carlquist 1974; Nogales et al. 2012, Vargas et al. 2015).

Manuscript received 19 October 2016; revised 26 February 2017; accepted 6 March 2017. Corresponding Editor: Gordon A. Fox.

${ }^{7}$ Corresponding Author. E-mail: arongcastro@gmail.com
The contribution of endozoochorous seed dispersal to plant recruitment or "seed dispersal effectiveness" (SDE, sensu Schupp et al. [2010]) is the product of the number of dispersed seeds (i.e., the quantitative component), and the probability that a dispersed seed becomes a new reproductive adult (i.e., the qualitative component). The quantitative component depends on frugivore abundance, feeding preferences, number of seeds per fruit, and availability of fruits to animals; whereas the qualitative component depends on both the direct effect of seed handling behavior, the treatment conferred to the seed in the frugivore gut, and the indirect effect determined by the quality of the deposition site, which is influenced by frugivore behavioral patterns (Traveset et al. 2014).

Most studies on seed dispersal have been either focused on the SDE of a single disperser species on several plants (Traveset et al. 2014), or on the SDE of several dispersers on a single plant species (Godínez-Á lvarez et al. 2002, Calviño-Cancela and Martín-Herrero 2009). In contrast, the SDE of a disperser community on a plant community (community SDE) has been seldom 
evaluated (but see Dennis and Westcott 2007, GonzálezCastro et al. 2015). The reason for this must be the labor-intensive field work and the complexity of the data (see Donatti et al. 2011, Schleuning et al. 2011). Oceanic islands, however, offer the opportunity to estimate community SDE in less complex systems (Nogales et al. 2016). On oceanic islands, we are only aware of one previous community-wide SDE study, which was carried out in a single habitat on the Canarian island of Tenerife (González-Castro et al. 2015). Thus, this study constitutes the first estimation of SDE at the level of the two main communities of plants and dispersers in the iconic oceanic archipelago of Galápagos.

In Galápagos, seed dispersal is carried out by at least 26 vertebrate species, belonging to guilds of small finches, lizards, giant tortoises, etc., strikingly different in morphology and ecology (Heleno et al. 2011, 2013). Understanding the relative contribution of each guild of dispersers in terms of their SDE is crucial to understand and preserve the functioning of insular ecosystems, where frugivore extinctions might compromise the longterm viability of plant populations; this is called oceanic island extinction debt (Tilman et al. 1994, Botzat et al. 2015). A failure to protect dispersal interactions might result in the accumulation of species on the way to extinction on some islands, so those plant species having lost their dispersers might be considered ecologically "the walking dead" (Valido 1999, Pérez-Méndez et al. 2016). Indeed, $90 \%$ of recorded bird extinctions and $75 \%$ of mammal extinctions have occurred on islands, despite these territories only representing $\sim 4 \%$ of the land surface of the globe (Gillespie and Clage 2009; Whittaker and Fernández-Palacios 2007).

The objective of this study was to evaluate the seed dispersal service provided by several functional groups of frugivores to the plant community in the two most widespread habitats of the Galápagos archipelago: the dry $(\sim 0-300 \mathrm{~m}$ above sea level) and the humid (>300 $\mathrm{m}$ above sea level) zones (Wiggins and Porter 1971). Specifically, we (1) described the overall pattern of frugivory and seed dispersal by the main disperser guilds and (2) estimated the quantitative and qualitative direct components of the SDE provided by disperser guilds to a representative group of fleshy-fruited plants.

\section{Methods}

\section{Study area}

The Galápagos Islands are located at the equator in the Eastern Pacific Ocean, $960 \mathrm{~km}$ west of South America. This volcanic archipelago is relatively young (3-4 million years; Ali and Aitchison 2014) and comprises 13 islands larger than $1 \mathrm{~km}^{2}$ and numerous islets. The Galápagos have a hot/wet season (January to May) and a cold/dry season (June to December). During the cold season, a frequent drizzle (or garúa) favors the development of the humid habitat in the highlands, while the lowlands are markedly dry. For an entire year, we evaluated animal seed dispersal at the community level on the two most human-populated islands of the Galápagos (Santa Cruz and San Cristóbal), encompassing the two main habitats (dry lowland and humid highland). Two study sites were chosen on each island (Santa Cruz: Puerto Ayora [lowland] and Media Luna [highland], and San Cristóbal: la Galapaguera [lowland] and El Junco [highland], for details see Heleno et al. 2013). Each site was visited twice per month during the main fruiting season (February-July), and once per month in the cold/ dry season.

We grouped the seed disperser species of our study $(n=18)$ into five guilds according to eco-morphological traits (Table 1): (1) the giant tortoise Chelonoidis chathamensis, (2) lava lizards Microlophus indefatigabilis

TABLE 1. Vertebrate species acting as seed dispersers on the studied islands.

\begin{tabular}{lcccc}
\hline \hline Vertebrate species & Common name & Relative size & Disperser guild & $\begin{array}{c}\text { Distribution in } \\
\text { Galápagos }\end{array}$ \\
\hline Chelonoidis chathamensis & San Cristóbal Giant Tortoise & large & tortoise & endemic \\
Microlophus indefatigabilis & Santa Cruz Lava Lizard & small & lava lizards & endemic \\
Microlophus bivittatus & San Cristóbal Lava Lizard & small & lava lizards & endemic \\
Mimus melanotis & San Cristóbal Mockingbird & medium & medium-sized passerines & endemic \\
Mimus parvulus & Galápagos Mockingbird & medium & medium-sized passerines & endemic \\
Crotophaga ani & Smooth-billed Ani & medium & medium-sized passerines & introduced \\
Myiarchus magnirostris & Galápagos Flycatcher & small & non-finches small passerines & endemic \\
Setophaga petechia & American Yellow warbler & small & non-finches small passerines & native \\
Camarhynchus pallidus & Woodpecker Finch & small & finches & endemic \\
Camarhynchus parvulus & Small Tree Finch & small & finches & endemic \\
Certhidea fusca & Grey Warbler Finch & small & finches & endemic \\
Certhidea olivacea & Green Warbler Finch & small & finches & endemic \\
Platyspiza crassirostris & Vegetarian Finch & small & finches & endemic \\
Geospiza fortis & Medium Ground Finch & small & finches & endemic \\
Geospiza fuliginosa & Small Ground Finch & small & finches & endemic \\
Geospiza magnirostris & Large Ground Finch & small & endemic \\
\hline
\end{tabular}


and M. bivittatus, (3) medium sized passerines (including mockingbirds and the introduced bird Crotophaga ani), (4) other non-finch small passerines, and (5) finches. Although we recorded seed dispersal for both fleshyfruited and dry-fruited plants, the quality of seed dispersal and thus the SDE were only estimated for the fleshy-fruited plant species, i.e., the endozoochorous ones.

\section{Sampling of disperser droppings}

At each study site, bird fecal samples were collected during 18 mist netting sessions and droppings from lava lizards ( $M$. indefatigabilis in Santa Cruz, and M. bivittatus in San Cristóbal) and tortoises (only present at la Galapaguera, San Cristóbal) were collected along two fixed $50 \times 2 \mathrm{~m}$ linear transects at each study site (eight transects in total) during each visit. These transects were placed along established pathways at each study site. All frugivore droppings were individually stored to evaluate the seed dispersal provided by the five frugivorous guilds. Intact seeds were identified with a stereoscope by comparison with material in a reference collection deposited at Charles Darwin Foundation (Jaramillo and Heleno 2012).

\section{Estimation of dispersal frequency and the quantity component of SDE}

We used the percentage of droppings containing at least one seed of any plant species (frequency of occurrence, hereafter FO) to estimate the frequency of seed dispersal provided by each of the five disperser guilds. We also calculated mean number of seeds per dropping (Appendix S1: Fig. S1). Although FO data are very intuitive and provide us with a first estimate of the frugivory level of animals, they are not adequate in a more accurate among-guild comparison of the quantitative component of SDE.

Here, the quantitative component of SDE is estimated as number of seeds dispersed per unit area by each animal species. To estimate the monthly number of seeds dispersed per square meter by tortoises and lizards at each of the four study sites, we divided the number of seeds found in droppings by the transect area $\left(100 \mathrm{~m}^{2}\right.$ per transect). As birds were captured by mist netting, we divided the number of dispersed seeds by the mist net area used to capture birds (length $\times$ height of all mist nets placed at each mist netting session). However, for tortoises and lizards, we sampled all observed droppings accumulated at transects every month, whereas sampling of bird droppings was only possible during mist netting sessions (from 7 to $26 \mathrm{~h} \cdot \mathrm{site}^{-1} \cdot \mathrm{month}^{-1}$ ). This might overestimate the quantity component of dispersal by tortoises and lizards compared to birds. Thus, we also divided the monthly number of seeds dispersed by tortoises and lizards by the hours that transects where accumulating droppings ( 12 daily hours $\times$ total days of the month) and divided the number of seeds dispersed by birds by the hours of mist netting session at each month. Therefore, the quantity component was estimated as the number of seeds dispersed $\cdot \mathrm{m}^{-2} \cdot \mathrm{h}^{-1}$. It enabled an accurate comparison of the quantitative component of seed dispersal provided by different disperser guilds. We present the results of FO and the quantity component for seeds of all plant species pooled, but detailed information for each plant species is provided in Appendix S1: Tables S1-S5.

\section{The qualitative component of SDE}

To evaluate the qualitative component of SDE, we focused on the direct effect of gut treatment on seedling emergence as one subcomponent of quality (Schupp et al. 2010). Seeds retrieved from droppings $(n=2922)$ were sown simultaneously in a shaded greenhouse at the Charles Darwin Research Station in Puerto Ayora on 1 April 2011, and their seedling emergence was followed for 2 yrs. In addition to the seeds extracted from the droppings of each animal species, a total of 1297 depulped-seeds from 22 plant species (ranging from 21 to 104 seeds per species) were collected from mature fruits and sown as control to evaluate the effect of each disperser guild compared to undigested seeds. All seeds were individually sown ( $5 \mathrm{~mm}$ deep) in a $4-\mathrm{cm}^{3}$ pot, containing a standard substrate $(50 \%$ culture soil, $25 \%$ turf and $25 \%$ volcanic ash-lapilli). In the greenhouse, the night/day cycle was similar to that under natural conditions. Pots were watered every second day (or daily on hot days). Germination trays were inspected daily during the first 6 months and then weekly until completing the 2 yrs. Seedling emergence was scored when any part of the seedling became visible above the soil surface.

\section{Direct contribution to seed dispersal effectiveness ( $S D E$ )}

We estimated the SDE as the product of the quantitative (seeds dispersed $\cdot \mathrm{m}^{-2} \cdot \mathrm{h}^{-1}$ ) and the qualitative (probability of seedling emergence) components (Schupp et al. 2010). We could not analyze the suitability of the deposition site for seedling emergence and survival (indirect subcomponent of quality) because it is highly context dependent and changes greatly under different environmental conditions (Schupp 2007). For this reason, our estimation should be considered as the direct contribution to SDE provided by dispersers. Therefore, we assume that there was no difference in the quality of seed deposition in order to make a direct comparison among the disperser guilds at different habitats. We estimated SDE as the number of recruited seedlings per square meter contributed by each disperser guild. This estimation of SDE only considered the guilds 'lizards' and 'medium-size passerines' because they provided a reliable sample size of dispersed seeds for most plant species. This sample size includes seeds from a total of 16 fleshy-fruited plant species. 


\section{Statistical analysis}

To assess if the frequency of occurrence of seeds differed among disperser guilds during the entire study year, we performed a categorical analysis (likelihood ratio $G$ test). For comparisons between pairs of dispersers we applied Bonferroni's correction factor. To test for among-guild differences in the quantitative component of the SDE, we performed a generalized linear mixed model (GLMM) with a normal error distribution, where number of seeds dispersed per square meter per hour (log-transformed) was the response variable, while disperser guild was the explanatory variable. In the model, study sites and time of sampling were set as random terms. To test for differences between pairs of disperser guilds, we applied Bonferroni's correction factor.

Statistically significant differences in the percentage of seedling emergence after gut treatment by the disperser guilds (qualitative component of the SDE) were evaluated by a categorical analysis (likelihood ratio $G$ test). We tested for the effect of both plant species and the disperser gut treatment. To test if guilds promoted different seedling emergence at the community level, regardless the identity of each plant species, we pooled emergence data of all plant species. On the other hand, when focusing on each plant species, we compared the seedling emergence of seeds from droppings vs. control seeds to assess if dispersers change the seedling emergence pattern.

To test for differences in the SDE provided by the disperser guilds, we applied a generalized linear mixed model (GLMM) with a normal error distribution. The response variable was the estimated SDE (log-transformed) provided by disperser guilds at each study site and time of sampling, while the explanatory variables were the disperser guild and plant species. In the model, we included site and time of sampling as random terms. To test for differences between pairs of disperser guilds, we applied Bonferroni's correction factor. We plotted the average SDE of each disperser-plant pair in a landscape graph using both the quantitative and qualitative components. Statistical analyses were performed with SPSS 20.0 for $G$ tests and with package nlme (Pinheiro et al. 2017) for R 3.3.2 (R Core Team 2016) in the case of the GLMMs.

\section{RESUlts}

\section{Frugivory and seed dispersal}

A total of 2960 droppings were analysed (2277 or $77 \%$ from birds and 683 or $23 \%$ from tortoises and lava lizards). One-third of the total $(n=875 ; 29.6 \%)$ contained at least one intact seed. Overall, 16 frugivore species dispersed 9159 seeds of 58 plant species (Appendix S1: Tables S1 to S3; see also Heleno et al. 2013). Although most plant species were dispersed by several disperser guilds, many of them $(n=23)$ were dispersed by just one or two disperser species.
Frequency of seed occurrence (FO) varied significantly among guilds $\left(G_{4}=149.40 ; P<0.001\right.$; Fig. 1a). Whereas FO was relatively similar for lava lizards, small passerines, and finches, it had its highest values for tortoises and medium passerines (Fig. 1a). The quantitative component of SDE (i.e., number of seeds dispersed $\cdot \mathrm{m}^{-2} \cdot \mathrm{h}^{-1}$ ) also varied significantly among disperser guilds $\left(\chi^{2}=123.33\right.$; $\mathrm{df}=4$; $P<0.001$; Fig. 1b). Specifically, it was two orders of magnitude higher for birds than lizards and tortoises (Fig. 1b). Among birds, non-finch small passerines dispersed more seeds, followed by finches and medium-sized passerines, although these differences were not significant (Fig. 1b).

\section{Effect of gut treatment on seedling emergence}

Overall, seedling emergence differed among plant species $\left(G_{21}=940.39 ; P<0.001 ;\right.$ Tables 2,3$)$. Regarding

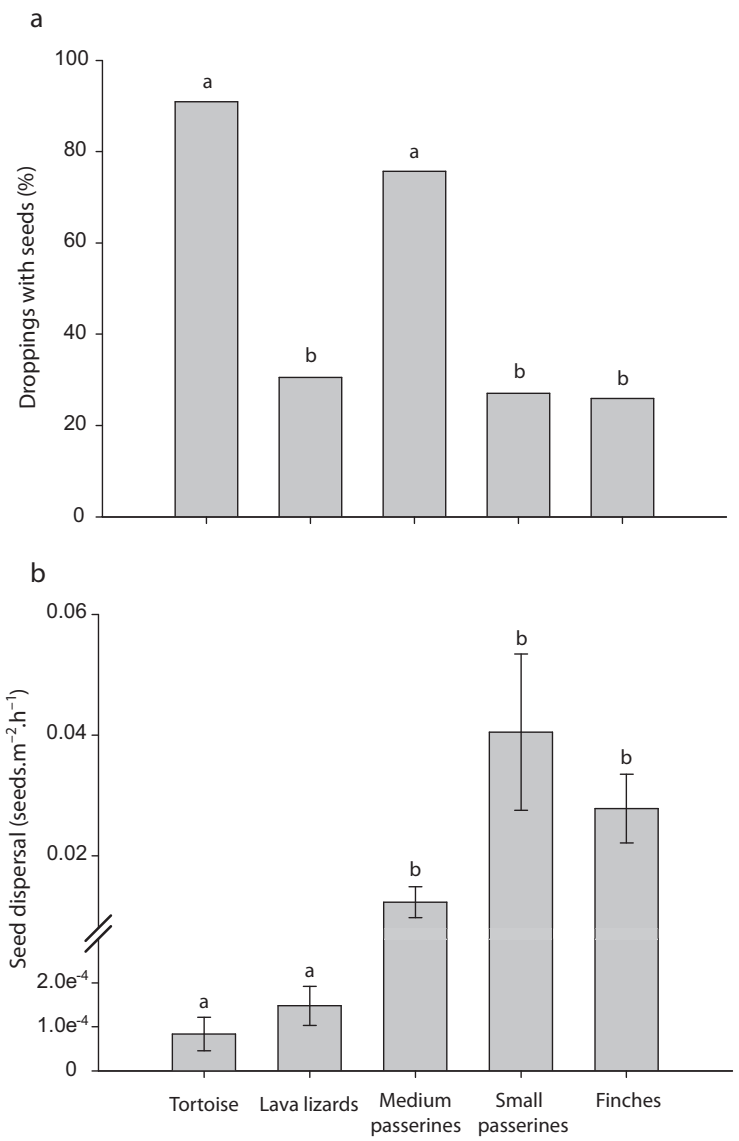

FIG. 1. Quantitative contribution of the different disperser guilds to seed dispersal in the Galápagos archipelago. (a) Frequency of occurrence of seeds in droppings from each disperser guild (measured as the percentage of droppings containing seeds). (b) Seed dispersal by each disperser guild (mean $\pm \mathrm{SE}$ ). Different letters at the top of bars refer to significant differences between disperser guilds, after applying Bonferroni's correction factor $(\alpha=0.005)$. 
seedling emergence promoted by dispersers' digestive treatment, only a relatively small proportion $(19.3 \% ; 563$ out of 2922) of the seeds retrieved from the droppings leaded to emergence. If data from all plant species were pooled, we observed that proportion of seedlings emergence varied among disperser guilds $\left(G_{4}=225.015\right.$; $P<0.001$; Fig. 2). Seeds from tortoises showed the highest emergence frequency, whereas seeds from small passerines had the lowest values.

For the six plant species dispersed by tortoises, we found no effect of tortoise gut passage compared to control seeds ( $G$ tests; all $P>0.05$; Tables 2,3 ). The effect of gut treatment by lava lizards significantly increased the percentage of seedling emergence compared to control seeds for three species: Lantana peduncularis, Tournefortia psilostachya, and Zanthoxylum fagara (Tables 2, 3), whereas they decreased it for another three species: Chiococca alba, Psidium guajaba, and Tournefortia pubescens (Tables 2, 3).

In the case of birds, seedling emergence experiments were carried out for 18 plant species dispersed by medium-sized passerines (Tables 2, 3). Ingested seeds from Bursera graveolens, Castela galapageia, and T. psilostachya had a higher emergence percentage than control seeds, whereas the opposite was found for $C$. alba, Momordica charantia, and T. pubescens (Tables 2, 3).
Seedling emergence of the remaining 12 plant species either did not differ significantly between ingested and controls or else no emergence was noted in both the treatment and control.

We also performed seedling emergence experiments for seven plant species dispersed by small passerines (Tables 2, 3). Ingested seeds from B. graveolens and $Z$. fagara had a higher emergence percentage $(\sim 29 \%)$ than controls, whereas ingested seeds from Lantana camara and $T$. pubescens had a lower emergence than controls. However, only a few seeds of B. graveolens and T. pubescens were found. Finally, emergence experiments were also carried out for seeds of Miconia robinsoniana, Rubus niveus, and T. psilostachya dispersed by finches. The only significant effect of the gut treatment by these birds was for $R$. niveus (Tables 2, 3).

\section{Direct contribution to seed dispersal effectiveness}

We compared the direct contribution to SDE provided by lava lizards and medium-sized passerines for 16 plant species (Appendix S1: Table S5). Looking at the community level (i.e., pooling data from all plant species), the quantitative component (seeds dispersed $\cdot \mathrm{m}^{-2} \cdot \mathrm{h}^{-1}$ ) was higher for medium passerines than for lava lizards $(1.83 \times$ $10^{-3} \pm 7.74 \times 10^{-4}$ and $2.11 \times 10^{-5} \pm 1.05 \times 10^{-5}$,

TABLE 2. Seedling emergence results (control seeds vs. seeds ingested by the tortoise and lava lizards).

\begin{tabular}{|c|c|c|c|c|c|c|c|}
\hline \multirow[b]{2}{*}{ Plant species } & \multirow{2}{*}{$\frac{\text { Control }}{\% \text { Germinated }} \begin{array}{c}\text { (germinated/ } \\
\text { sown seeds) }\end{array}$} & \multicolumn{3}{|c|}{ Tortoise } & \multicolumn{3}{|c|}{ Lava lizards } \\
\hline & & $\begin{array}{l}\% \text { Germinated } \\
\text { (germinated/ } \\
\text { sown seeds) }\end{array}$ & $G$ & $P$ & $\begin{array}{l}\% \text { Germinated } \\
\text { (germinated/ } \\
\text { sown seeds) }\end{array}$ & $G$ & $P$ \\
\hline Bursera graveolens & $8(4 / 52)$ & $22(2 / 9)$ & 1.48 & 0.22 & $0(0 / 2)$ & 0.31 & 0.57 \\
\hline Castela galapageia & $8(4 / 52)$ & - & - & - & - & - & - \\
\hline Chiococca alba & $52(27 / 52)$ & - & - & - & $26(21 / 80)$ & 8.93 & 0.003 \\
\hline Clerodendrum molle & $12(6 / 52)$ & - & - & - & - & - & - \\
\hline Cordia leucophlyctis & $0(0 / 52)$ & - & - & - & $4(1 / 25)$ & 2.27 & 0.13 \\
\hline Cordia lutea & $40(19 / 47)$ & - & - & - & $0(0 / 2)$ & 2.01 & 0.15 \\
\hline Hippomane mancinella & $33(10 / 30)$ & $50(26 / 52)$ & 2.17 & 0.14 & - & - & - \\
\hline Lantana camara $\dagger$ & $12(6 / 52)$ & $0(0 / 5)$ & 1.16 & 0.28 & $8(4 / 52)$ & 0.44 & 0.50 \\
\hline Lantana peduncularis & $0(0 / 52)$ & - & - & - & $13(2 / 15)$ & 6.20 & 0.01 \\
\hline Miconia robinsoniana & $1(1 / 104)$ & - & - & - & - & - & - \\
\hline Momordica charantia $\dagger$ & $67(35 / 52)$ & - & - & - & $50(1 / 2)$ & 0.24 & 0.62 \\
\hline Opuntia echios & $23(10 / 43)$ & - & - & - & $0(0 / 2)$ & 1.03 & 0.31 \\
\hline Passiflora foetida & $35(18 / 52)$ & $0(0 / 1)$ & 0.84 & 0.35 & $100(1 / 1)$ & 2.08 & 0.14 \\
\hline Psidium galapageium & $45(47 / 104)$ & $44(46 / 104)$ & 0.01 & 0.88 & - & - & - \\
\hline Psidium guajaba & $81(42 / 52)$ & $100(1 / 1)$ & 0.42 & 0.51 & $0(0 / 3)$ & 9.24 & 0.002 \\
\hline Rubus niveus $\dagger$ & $13(14 / 104)$ & - & - & - & $0(0 / 4)$ & 1.13 & 0.28 \\
\hline Scutia spicata & $31(16 / 52)$ & - & - & - & $50(6 / 12)$ & 1.53 & 0.21 \\
\hline Tournefortia psilostachya & $2(1 / 52)$ & - & - & - & $27(28 / 104)$ & 18.7 & $<0.001$ \\
\hline Tournefortia pubescens & $63(33 / 52)$ & - & - & - & $24(12 / 51)$ & 17.2 & $<0.001$ \\
\hline Tournefortia rufo-sericea & $17(9 / 52)$ & - & - & - & $0(0 / 1)$ & 0.37 & 0.54 \\
\hline Vallesia glabra & $13(3 / 21)$ & - & - & - & $100(1 / 1)$ & 3.89 & 0.05 \\
\hline Zanthoxylum fagara & $1(1 / 104)$ & - & - & - & $7(4 / 54)$ & 4.57 & 0.03 \\
\hline
\end{tabular}

Notes: Likelihood ratio ( $G$ test) and $P$-values refer to comparison between control seeds and seeds ingested by each disperser. Values for significant differences are in bold.

$\dagger$ Alien plant species. 
TABLE 3. Seedling emergence results (seeds ingested by medium and small passerines).

\begin{tabular}{|c|c|c|c|c|c|c|c|c|c|}
\hline \multirow[b]{2}{*}{ Plant species } & \multicolumn{3}{|c|}{ Medium passerines } & \multicolumn{3}{|c|}{ Small passerines (non-finches) } & \multicolumn{3}{|c|}{ Small passerines (finches) } \\
\hline & $\begin{array}{l}\% \text { Germinated } \\
\text { (germinated/ } \\
\text { sown seeds) }\end{array}$ & $G$ & $P$ & $\begin{array}{l}\% \text { Germinated } \\
\text { (germinated/ } \\
\text { sown seeds) }\end{array}$ & $G$ & $P$ & $\begin{array}{l}\% \text { Germinated } \\
\text { (germinated/ } \\
\text { sown seeds) }\end{array}$ & $G$ & $P$ \\
\hline Bursera graveolens & $67(6 / 9)$ & 14.76 & $<0.001$ & $100(1 / 1)$ & 4.91 & 0.02 & - & - & - \\
\hline Castela galapageia & $48(12 / 25)$ & 15.87 & $<0.001$ & - & - & - & - & - & - \\
\hline Chiococca alba & $2(2 / 109)$ & 59.88 & $<0.001$ & - & - & - & - & - & - \\
\hline Clerodendrum molle & - & - & - & - & - & - & - & - & - \\
\hline Cordia leucophlyctis & $0(0 / 1)$ & NA & NA & - & - & - & - & - & - \\
\hline Cordia lutea & $33(1 / 3)$ & 0.80 & 0.06 & - & - & - & - & - & - \\
\hline Hippomane mancinella & - & - & - & - & - & - & - & - & - \\
\hline Lantana camara & $0(0 / 5)$ & 1.17 & 0.28 & $0(0 / 25)$ & 4.95 & 0.02 & - & - & - \\
\hline Lantana peduncularis & $0(0 / 4)$ & NA & NA & - & - & - & - & - & - \\
\hline Miconia robinsoniana & $0(0 / 335)$ & 2.89 & 0.09 & $0.5(1 / 208)$ & 0.23 & 0.62 & $0.3(2 / 608)$ & 0.66 & 0.41 \\
\hline Momordica charantia $\dagger$ & $20(1 / 5)$ & 4.29 & 0.03 & - & - & - & - & - & - \\
\hline Opuntia echios & - & - & - & - & - & - & - & - & - \\
\hline Passiflora foetida & $50(1 / 2)$ & 0.002 & 0.96 & - & - & - & - & - & - \\
\hline Psidium galapageium & - & - & - & - & - & - & - & - & - \\
\hline Psidium guajaba $\dagger$ & $75(3 / 4)$ & 0.07 & 0.78 & - & - & - & - & - & - \\
\hline Rubus niveus $\dagger$ & $21(8 / 38)$ & 1.16 & 0.28 & - & - & - & $41(29 / 70)$ & 17.43 & $<0.001$ \\
\hline Scutia spicata & $30(3 / 10)$ & 0.002 & 0.96 & - & - & - & - & - & - \\
\hline Tournefortia psilostachya & $12(17 / 148)$ & 5.58 & 0.01 & $7(4 / 59)$ & 1.63 & 0.20 & $0(0 / 9)$ & 0.32 & 0.57 \\
\hline Tournefortia pubescens & $11(6 / 57)$ & 35.53 & $<0.001$ & $0(0 / 3)$ & 5.76 & 0.01 & - & - & - \\
\hline Tournefortia rufo-sericea & $0(0 / 3)$ & 1.10 & 0.29 & - & - & - & - & - & - \\
\hline Vallesia glabra & $0(0 / 3)$ & 0.75 & 0.38 & $0(0 / 1)$ & 0.26 & 0.60 & - & - & - \\
\hline Zanthoxylum fagara & $0(0 / 32)$ & 0.539 & 0.46 & $7(4 / 56)$ & 4.40 & 0.03 & - & - & - \\
\hline
\end{tabular}

Notes: Likelihood ratio ( $G$ test) and $P$-values refer to comparison between control seeds and seeds ingested by each disperser. Values for significant differences are in bold. NA: cases where the analysis was not possible due to no seedling emergence for any of the treatments compared.

$\dagger$ Alien plant species.

respectively [mean $\pm \mathrm{SE}]$; Fig. 3; Appendix S1: Table S5), whereas the qualitative component (probability of seedling emergence) was higher for lizards than for medium passerines $(0.25 \pm 0.08$ and $0.20 \pm 0.06$, respectively; Fig. 3; Appendix S1: Table S5). Overall, medium passerines promoted a higher SDE than lava lizards $(2.30 \times$ $10^{-4} \pm 9.15 \times 10^{-5}$ and $4.50 \times 10^{-6} \pm 2.83 \times 10^{-6}$, respectively; Fig. 3).

Considering the SDE for each plant species separately, the likelihood ratio (LR) test of the GLM showed a significant effect of disperser guilds $\left(\mathrm{LR}_{2}=41.50 ; P<\right.$ $0.001)$, plant species $\left(\mathrm{LR}_{15}=103.15 ; P<0.001\right)$, and their statistical interaction $\left(\mathrm{LR}_{15}=73.63 ; P<0.001\right)$. Medium passerines provided a higher SDE than lizards for 10 plant species (Fig. 3; Appendix S1: Table S5), namely Bursera graveolens, Chiococca alba, Cordia lutea, Momordica charantia, Passiflora foetida, Psidium guajaba, Rubus niveus, Scutia spicata, Tournefortia psilostachya, and T. pubescens. In contrast, lava lizards provided a higher SDE for five plant species: Cordia leucophlyctis, Lantana camara, L. peduncularis, Vallesia glabra, and Zanthoxylum fagara (Fig. 3; Appendix S1: Table S5). None of the seeds of Tournefortia rufo-sericea dispersed by medium passerines and lizards emerged.

\section{Discussion}

At least 16 vertebrate species influence plant regeneration in the Galápagos Islands by consuming fruits and dispersing seeds from at least 58 plant species. However, our data on the quantitative and qualitative components of dispersal effectiveness SDE, show that some vertebrate species play a much more prominent role as seed dispersers than others.

\section{Frugivory and dissemination}

Almost all fleshy-fruited plants were dispersed by more than one disperser guild, although some of them only had a single disperser species. Such finding agrees with González-Castro et al. (2015) who reported a similar result for the Canary Islands. Those asymmetrical relationships of plant species depending on just one frugivore that disperse many plant species are very vulnerable against disperser extinctions (Rumeu et al. 2017). Such a fragile interaction profile is common on islands, e.g., Calvaria major in Mauritius (Witmer 1991), Neochamaelea pulverulenta in the Canaries (Valido 1999, Pérez-Méndez et al. 2016), Cneorum tricoccon in the Balearic Islands 


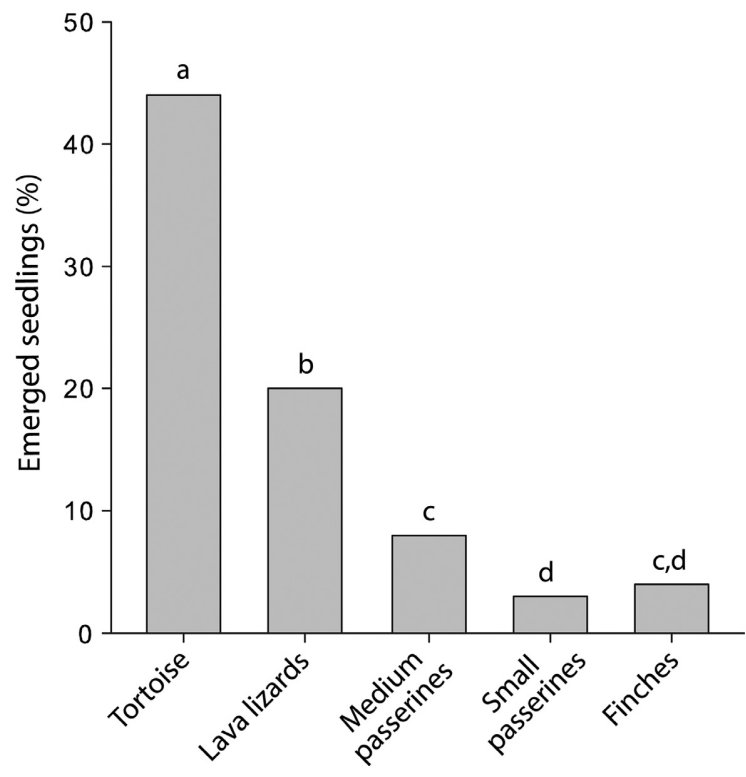

FIG. 2. Qualitative contribution of Galápagos frugivores to seed dispersal measured as the percentage of seedling emergence in the greenhouse experiment after ingestion by each disperser guild. This figure shows the direct effect of dispersers gut treatment on the plant community, regardless the identity of each plant species. Different letters at the top of bars refer to significant differences between pairs of disperser guilds, after applying Bonferroni's correction factor $(\alpha=0.005)$.

(Traveset and Riera 2005), and most likely for some of the many endangered native plants from the Hawaiian Islands, whose dispersal may depend on Corvus hawaiiensis, which is now extinct in the wild (Culliney et al. 2012).

Giant tortoises are known to play a key role as disperser on oceanic islands, e.g., Mauritius (Hansen et al. 2008) and Aldabra (Hnatiuk 1978). Based on the frequency of seed dispersal (frequency of occurrence), the large number of seeds dispersed per dropping and seed germinability, the giant tortoise may play the same role on the Galápagos.

Lava lizards were also active frugivores and moved seeds from at least 26 identified plants (Heleno et al. 2013), clearly disproving the long-standing view that these animals were strict insectivores (Jackson 1994). Indeed, our results are consistent with those of other studies showing the importance of lizards as seed dispersers on other tropical and subtropical islands with xeric habitats (Olesen and Valido 2003, Zuel et al. 2012).

Among birds, one of the most important seed disperser guilds was medium sized non-finch passerines, especially the omnivorous mockingbirds (Mimus spp.), which dispersed seeds of at least 19 species. Mainland mockingbirds are also omnivorous (Jackson 1994), but their role as seed dispersers may be more pronounced in the Galápagos (Heleno et al. 2011, 2013). Their medium body size and versatile beak allows them to consume a wider range of size and shape of fruits and seeds. Among the small non-finch passerines, the warbler Setophaga petechia and the flycatcher Myiarchus magnirostris were important seed dispersers (Heleno et al. 2013), moving intact seeds of 8 and 11 species, respectively (Appendix S1: Table S2). Both species have traditionally been considered as mainly insectivorous in continental areas (Jackson [1997] for M. magnirostris, Morse [1989] for $S$. petechia). Species in the finch group dispersed seeds of at least 25 species. Camarhynchus parvulus and Geospiza fuliginosa were the most important dispersers among the tree and ground finches, respectively (Appendix S1: Tables S3 and S4). While ground finches mostly dispersed seeds from dry-fruited plants, Tree

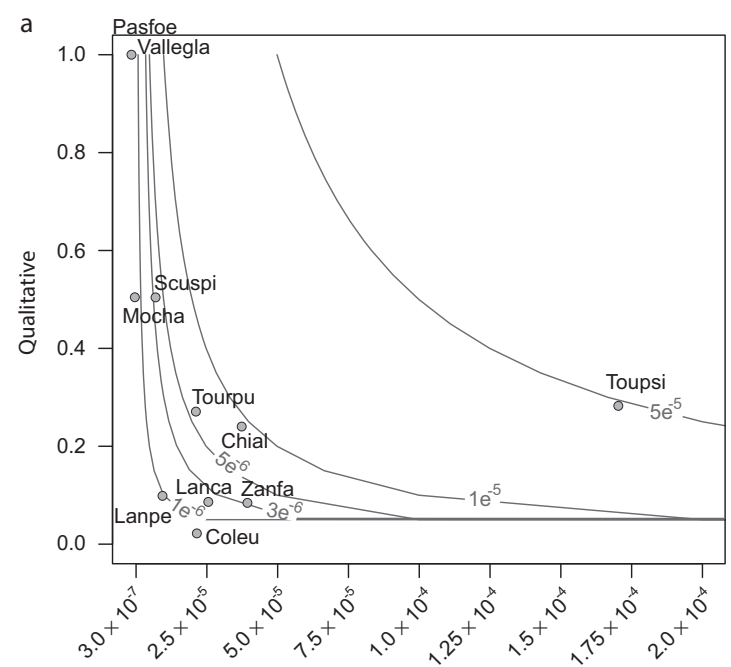

b

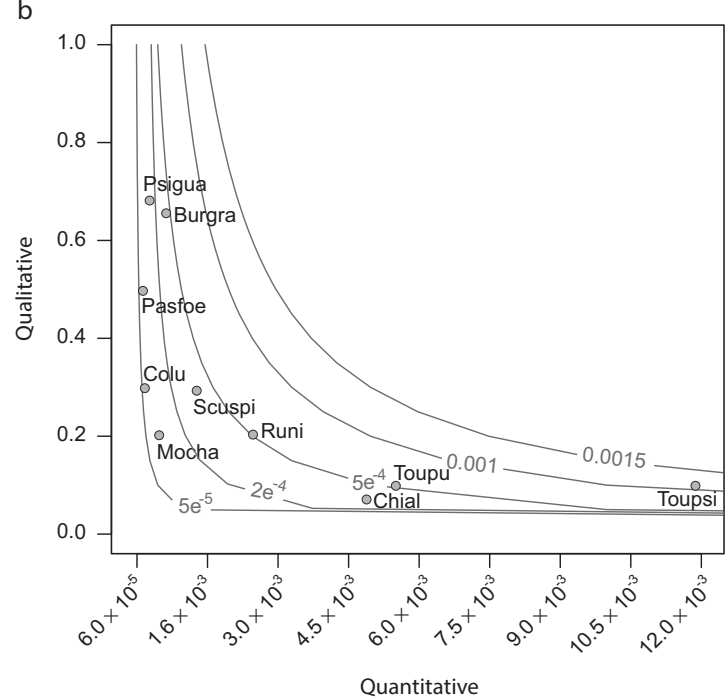

FIG. 3. Quantitative (mean number of seeds dispersed $\cdot \mathrm{m}^{-2} \cdot \mathrm{h}^{-1}$ ), qualitative (emergence probability of dispersed seeds) components, and seed dispersal effectiveness (SDE) provided by (a) lava lizards and (b) medium-sized passerines in the Galápagos. Isoclines join points with the same seed dispersal effectiveness (number of seedlings $/ \mathrm{m}^{2}$ ) within the twodimensional space. Plant species are coded by the first 2 or 3 letters of their genus and species names, respectively. For clarity, only interactions with $\mathrm{SDE}>0$ are shown. 
Finches dispersed seeds of both dry and fleshy-fruited plant species (Heleno et al. 2013). The role of Galápagos finches as seed dispersers has also been demonstrated by Guerrero and Tye (2009) for seven finch species and, in particular for the two herbivores Camarhynchus pallidus and Certhidea olivacea. In other archipelagos (e.g., the Azores) and mainland environments, some granivores legitimately disperse some of the seeds they ingest (Heleno et al. 2011, Orlowski et al. 2015).

Interestingly, a clearly different pattern of seed dispersal emerges when the number of seeds dispersed $\cdot \mathrm{m}^{-2} \cdot \mathrm{h}^{-1}$ is considered, (Fig. 1b). Now, small passerines (finches and non-finches) are most important, followed by medium-sized passerines (Fig. 1b), whereas giant tortoises and lava lizards play minor roles. This difference might be caused by body size variation. Larger dispersers usually have longer retention times and larger home ranges than smaller dispersers. It has been reported that Galápagos giant tortoises have an average gut retention time of 6.6-11.9 d (Sadeghayobi et al. 2011), whereas lizards of different families, but of a size similar to Microlophus sp., have a much lower retention time of 20.1-23.7 h (Hatch and Afik 1999) or $2.4 \mathrm{~d}$ (Valido and Nogales 2003). Galápagos mockingbirds retain seeds for 87 min (Buddenhagen and Jewell 2006), whereas retention time in small passerines is only 5-20 min for regurgitated seeds and from $18 \mathrm{~min}$ up to $1.5 \mathrm{~h}$ for defecated seeds (Jordano 2000). Additionally, body size is positively related to home range (Perry and Garland 2002, Ottaviani et al. 2006). Therefore, relatively large animals (giant tortoises and mockingbirds) can disperse seeds clumped in larger and less frequent droppings than smaller animals, which might lead to a higher FO and number of seeds per droppings (Fig. 1a, Appendix S1: Fig. S1), across a larger area with a lower density of seeds dispersed (i.e., seeds $\cdot \mathrm{m}^{-2} \cdot \mathrm{h}^{-1}$; Fig. 1b). Indeed, Blake et al. (2012) found that giant tortoises in the Galápagos disperse seeds of more than 45 plant species over long distances, including movements greater than $4 \mathrm{~km}$.

\section{Effect of gut treatment on seedling emergence}

Our results show that ingestion and dispersal by different vertebrate species can add an additional layer of variability to seed fate, caused by detriment/enhancement of germination as well as variation in seed deposition sites (Traveset 1998, González-Castro et al. 2015). These differences might potentially improve overall plant fitness by increasing the likelihood that a proportion of seeds will encounter appropriate germination conditions ("don't put all your eggs in the same basket" effect; Moore 2001).

\section{The direct contribution to SDE provided by lava lizards and medium-sized passerines}

Overall, birds contributed more to SDE than lizards (Fig. 3; Appendix S1: Table S4). Medium-sized passerines were quantitatively more important dispersers than lava lizards (Fig. 3), although the qualitative contribution in terms of emergence probability was slightly higher for lizards. In contrast, González-Castro et al. (2015) found a higher contribution of lizards in the Canary Islands for both components of SDE and the reasons for this interarchipelago variation needs further studies.

In any case, the significant statistical interaction between plant species and disperser guilds to determine the SDE shows that the direct contribution by each disperser guild to the SDE must be considered in a single-plant species context. When considering each plant species, medium-sized passerine birds were still more important as they provided higher contribution to SDE than lizards in 10 out of the 16 plant species in our studied communities (Fig. 3; Appendix S1: Table S4). In six plant species, birds provided a contribution to SDE at least one order of magnitude higher than lizards despite the quality provided by lizards was higher. This is due to the huge amount of seeds dispersed by birds $\cdot \mathrm{m}^{-2} \cdot \mathrm{h}^{-1}$ ). Although previous studies have demonstrated a greater effect of quality than quantity on plant recruitment (Calviño-Cancela and Martín-Herrero 2009, GonzálezCastro et al. 2015), we found that quantity had a stronger effect on seedling recruitment than quality in the case of Galápagos dispersers. One reason for this divergent result is methodological, because our approach is exclusively focused on the direct effects of dispersers on seedling emergence, whereas the other two studies also focused on the quality of the seed deposition site.

\section{Concluding remarks}

On this iconic oceanic archipelago, we demonstrated that Microlophus lava lizards not only disperse seeds (Heleno et al. 2013), but they are also effective dispersers, promoting enhanced seedling emergence for the local plant communities. Therefore, the ecological role of all nine Microlophus species, allopatrically distributed in different islands, needs further study. The markedly contrasting pattern showed in the quantitative component of seed dispersal (frequency of seeds occurrence vs. number of seeds dispersed $\cdot \mathrm{m}^{-2} \cdot \mathrm{h}^{-1}$ ) may have important consequences for the dispersal services provided by different disperser guilds. Therefore, further studies on SDE provided by disperser guilds with clearly different body sizes should explicitly address the extent of disperser spatial displacement (Spiegel and Nathan 2007), as well as the quality of seed deposition sites for seedling emergence and survival.

The information about the quantitative and qualitative components of SDE showed in the two-dimensional landscape of the SDE (Fig. 3) and in the Appendix S1: Table S5 indicate that some plant species depend more on lizards than on birds, and vice versa, with differences of at least one order of magnitude. It has important consequences because plant species relying on a single disperser species are common in island habitats worldwide 
and such specialized dependency makes the plants more vulnerable to the extinction of their dispersers.

Amidst the rapid global changes characterizing the Anthropocene, and particularly on islands, it is vital to understand how mutualistic interactions shape the diversity and long-term dynamics of ecosystems and the services they provide.

\section{ACKNOWLEDGMENTS}

Erika Zambrano collaborated during the germination experiments. Washington Tapia, Eugene W. Schupp, and an anonymous reviewer made useful comments and suggestions on a previous version of the manuscript. This study is framed within a biodiversity project in the Galápagos Islands, partially financed by Foundación BBVA (Spain) and the projects CGL2012-C02-01 and CGL2013-44386-P funded by the Ministerio de Economía y Competitividad (Spain). We thank Foundación Charles Darwin and Parque Nacional de Galápagos (permission number: PC-026-09) for offering us information and logistic support. R. Heleno was funded by the grant IF/00441/2013 from Fundação para a Ciência e a Tecnologia (Portugal) and the Marie-Curie CIG-321794. M. Nogales and A. González-Castro contributed equally to this work.

\section{Literature Cited}

Ali, J. R., and J. C. Aitchison. 2014. Exploring the combined role of eustasy and oceanic island thermal subsidence in shaping biodiversity on the Galápagos. Journal of Biogeography 41:1227-1241.

Blake, S., M. Wikelski, F. Cabrera, A. Guezou, M. Silva, E. Sadeghayobi, and P. Jaramillo. 2012. Seed dispersal by Galápagos tortoises. Journal of Biogeography 39:1961-1972.

Botzat, A., L. Fischer, and N. Farwig. 2015. Regeneration potential in South African forest fragments: extinction debt paid off or hampered by contemporary matrix modification? Plant Ecology 216:535-551.

Buddenhagen, C., and K. J. Jewell. 2006. Invasive plant seed viability after processing by some endemic Galapagos birds. Ornitologia Tropical 17:73-80.

Calviño-Cancela, M., and J. Martín-Herrero. 2009. Effectiveness of a varied assemblage of seed dispersers of a fleshyfruited plant. Ecology 90:3503-3515.

Carlquist, S. J. 1974. Island biology. Columbia University Press, New York, New York, USA.

Culliney, S., L. Pejchar, R. Switzer, and V. Ruíz-Gutiérrez. 2012. Seed dispersal by a captive corvid: the role of the 'Alala (Corvus hawaiiensis) in shaping Hawai'i’s plant communities. Ecological Applications 22:1718-1732.

Dennis, A. J., and D. A. Westcott. 2007. Estimating dispersal kernels produced by a diverse community of vertebrates. Pages 201-228 in A. J. Dennis, E. W. Schupp, R. A. Green, and D. A. Westcott, editors. Seed dispersal: theory and its application in a changing world. CAB International, Wallingford, UK.

Donatti, C. I., P. R. Guimarães, M. Galetti, M. A. Pizo, F. M. D. Marquitti, and R. Dirzo. 2011. Analysis of a hyper-diverse seed dispersal network: modularity and underlying mechanisms. Ecology Letters 14:773-781.

Gillespie, R. G., and D. A. Clague. 2009. Encyclopaedia of islands. University of California Press, Berkley, California, USA.

Godínez-Álvarez, H., A. Valiente-Banuet, and A. RojasMartínez. 2002. The role of seed dispersers in the population dynamics of the columnar cactus Neobuxbaumia tetetzo. Ecology 83:2617-2629.
González-Castro, A., M. Calviño-Cancela, and M. Nogales. 2015. Comparing seed dispersal effectiveness by frugivores at the community level. Ecology 96:808-818.

Gorman, M. 1979. Island ecology. Chapman and Hall, London, UK.

Guerrero, A. M., and A. Tye. 2009. Darwin's finches as seed predators and dispersers. Wilson Journal of Ornithology 121: 752-764.

Hansen, D. M., C. N. Kaiser-Bunbury, and C. B. Müller. 2008. Seed dispersal and establishment of endangered plants on oceanic islands: the Janzen-Connell model, and the use of ecological analogues. PLoS ONE 3:e.2111.

Hatch, K. A., and D. Afik. 1999. Retention time of digesta in insectivorous lizards - a comparison of methods and species. Comparative Biochemistry and Physiology Part A 124:89-92.

Heleno, R., S. Blake, P. Jaramillo, A. Traveset, P. Vargas, and M. Nogales. 2011. Frugivory and seed dispersal in the Galápagos: what is the state of the art? Integrative Zoology 6:110-129

Heleno, R., J. M. Olesen, M. Nogales, P. Vargas, and A. Traveset. 2013. Seed dispersal networks in the Galápagos and the consequences of alien plant invasions. Proceedings of the Royal Society B 280:20122112.

Hnatiuk, S. H. 1978. Plant dispersal by the Aldabra tortoise, Geochelone gigantea (Scheigger). Oecologia 36:345-350.

Jackson, M. H. 1994. Galapagos: a natural history, revised and expanded. University of Calgary Press, Calgary, Alberta, Canada.

Jaramillo, P., and R. Heleno. 2012. Guía rápida de semillas de las islas Galápagos. Fundación Charles Darwin, Puerto Ayora, Ecuador.

Jordano, P. 2000. Fruits and frugivores. Pages 125-165 in M. Fenner, editor. Seeds: the ecology of regeneration in plant communities, second edition. CAB International, Oxford, UK.

Moore, P. D. 2001. Ecology: the guts of seed dispersal. Nature 414:406-407.

Morse, D. H. 1989. American warblers: an ecological and behavioral perspective. Harvard University Press, Cambridge, Massachusetts, USA.

Nogales, M., R. Heleno, B. Rumeu, A. González-Castro, A. Traveset, P. Vargas, and J. M. Olesen. 2016. Seed-dispersal networks on the Canaries and the Galápagos: interaction modules as biogeographical entities. Global Ecology and Biogeography 25:912-922.

Nogales, M., R. Heleno, A. Traveset, and P. Vargas. 2012. Evidence for overlooked mechanisms of long-distance seed dispersal to and between oceanic islands. New Phytologist 194:313-317.

Olesen, J., and A. Valido. 2003. Lizards as pollinators and seed dispersers: an island phenomenon. Trend in Ecology and Evolution 18:177-181.

Orlowski, G., J. Czarnecka, A. Golawski, J. Karg, and M. Panek. 2015. The effectiveness of endozoochory in three avian seed predators. Journal of Ornithology 157:61-73.

Ottaviani, D., S. C. Cairns, M. Oliveiro, and L. Boitani. 2006. Body mass as a predictive variable of home-range size among Italian mammals and birds. Journal of Zoology 269:317-330.

Pérez-Méndez, N., P. Jordano, C. García, and A. Valido. 2016. The signatures of Anthropocene defaunation: cascading effects of the seed dispersal collapse. Scientific Report 6: 24820.

Perry, G., and T. Jr Garland. 2002. Lizard home ranges revisited: effects of sex, body size, diet habitat, and phylogeny. Ecology 83:1870-1885.

Pinheiro, J., D. Bates, S. DebRoy, D. Sarkar, and R Core Team. 2017. nlme: linear and nonlinear mixed effects models. 
R package version 3.1-131, https://CRAN.R-project.org/pack age $=$ nlme

R Core Team. 2016. R: a language and environment for statistical computing. R Foundation for Statistical Computing, Vienna, Austria. www.r-project.org

Ridley, H. N. 1930. The dispersal of plants throughout the world. L. Reeve and Co., Kent, UK.

Rumeu, B., M. Devoto, A. Traveset, J. M. Olesen, P. Vargas, M. Nogales, and R. H. Heleno. in press. Predicting the consequences of disperser extinction: richness matters the most when abundance is low. Functional Ecology. https://doi.org/ $10.1111 / 1365-2435.12897$

Sadeghayobi, E., S. Blake, M. Wikelski, J. Gibbs, R. Mackie, and F. Cabrera. 2011. Digesta retention time in the Galápagos tortoise (Chelonoidis nigra). Comparative Biochemistry and Physiology, Part A 160:493-4997.

Schleuning, M., N. Blüthgen, M. Flörchinger, J. Braun, H. M Schaefer, and K. Böhning-Gaese. 2011. Specialization and interaction strength in a tropical plant-frugivore network differ among forest strata. Ecology 92:26-36.

Schupp, E. W. 2007. The suitability of a site for seed dispersal is context-dependent. Pages $445-461$ in A. J. Dennis, E. W. Schupp, R. A. Green, and D. A. Westcott, editors. Seed dispersal: theory and its application in a changing world. CAB International, Wallingford, UK.

Schupp, E. W., P. Jordano, and J. M. Gómez. 2010. Seed dispersal effectiveness revisited: a conceptual review. New Phytologist 188:333-353.

Spiegel, O., and R. Nathan. 2007. Incorporating dispersal distance into the disperser effectiveness framework: frugivorous birds provide complementary dispersal to plants in a patchy environment. Ecology Letters 10:718-728.

Tilman, D., R. M. May, C. L. Lehman, and M. A. Novak. 1994. Habitat destruction and the extinction debt. Nature 371:64-65.
Traveset, A. 1998. Effect of seed passage through vertebrate frugivores' guts on germination: a review. Perspectives in Plant Ecology, Evolution and Systematics 1(2):151-190.

Traveset, A., R. Heleno, and M. Nogales. 2014. The ecology of seed dispersal. Pages 62-93 in R. S. Gallagher, editor. Seeds: the ecology of regeneration in plant communities. CABI International, Wallingford, UK.

Traveset, A., and N. Riera. 2005. Disruption of a plant-lizard seed dispersal system and its ecological effects on a threatened endemic plant in the Balearic Islands. Conservation Biology 19:421-431.

Valido, A. 1999. Ecología de la dispersión de semillas por los lagartos endémicos canarios (G. Galloti, Lacertidae). Dissertation. Universidad de La Laguna, Tenerife.

Valido, A., and M. Nogales. 2003. Digestive ecology of two omnivorous Canarian lizard species (Gallotia, Lacertidae). Amphibia-Reptilia 24:331-344.

Van der Pijl, L. 1982. Principles of dispersal of higher plants. Springer, Berlin, Germany.

Vargas, P., Y. Arjona, M. Nogales, and R. Heleno. 2015. Longdistance dispersal to oceanic islands: success of plants with multiple diaspore specializations. AoB Plants 7:plv073.

Whittaker, R. J., and J. M. Fernández-Palacios. 2007. Island biogeography. Oxford University Press, Oxford, UK.

Wiggins, I. L., and D. M. Porter. 1971. Flora of the Galápagos Islands. Stanford University Press, Stanford, California, USA.

Witmer, M. C. 1991. The dodo and the tambalacoque tree: an obligate mutualism reconsidered. Oikos 61:33-137.

Zuel, N., C. J. Griffiths, A. Hector, D. Hansen, C. G. Jones, and M. Albrecht. 2012. Ingestion by an endemic frugivore enhances seed germination of endemic plant species but decreases seedling survival of exotics. Journal of Biogeography 39:2021-2030.

\section{SUPPORTING INFORMATION}

Additional supporting information may be found in the online version of this article at http://onlinelibrary.wiley.com/doi/ 10.1002/ecy.1816/suppinfo 